Çukurova Üniversitesi Mühendislik Mimarlık Fakültesi Dergisi, 31(2), ss. 209-216, Aralık 2016

\title{
Geçirimli Betonların Basınç Dayanımı Üzerine Deneysel Bir Çalışma
}

\author{
Ahmet AKKAYA *1 , İsmail Hakkı ÇAĞATAY ${ }^{1}$ \\ ${ }^{1}$ Çukurova Üniversitesi, Mühendislik Mimarlık Fakültesi, İnşaat Mühendisliği Bölümü, Adana
}

Geliş tarihi: 06.06.2016 Kabul tarihi: 23.11.2016

\section{$\ddot{\mathbf{O} z}$}

Tükenen kaynakları koruma ve doğa üzerindeki insan etkisini azaltma çabası sonucunda son yıllarda geçirimli betonlar popülerlik kazanmıştır. Özellikle yer altı su kaynaklarını beslemesi, kirleticiler ve 1sı adası etkisini azaltması geçirimli betonların avantajları arasında sayılabilir. Sınırlı dayanım özelliklerinden dolayı, bugüne kadar geleneksel betonlar kadar kullanılmamışlardır. Ancak, katkı malzemeleri teknolojisindeki gelişim ve artan çevre bilinciyle birlikte geçirimli betonların adı eskiden olmadığı kadar fazla duyulmaktadır. Bu çalışmada geçirimli betonların fiziksel özelliklerini etkileyen önemli parametrelerden gradasyonun basınç dayanımına etkisi incelenmiştir. Çalışmanın sonucunda kum eklenmesinin basınç dayanımını ciddi oranda arttırabileceği görülmüştür. Ancak, ön deneyler yapılarak kum eklenmesi eşik değerinin belirlenmesi gerekmektedir.

Anahtar Kelimeler: Geçirimli beton, Geçirimli beton teknolojisi, Permeabilite

\section{An Experimental Study on Compressive Strength of Pervious Concretes}

\begin{abstract}
Pervious concretes have gained popularity in recent years, because of human effort to protect depleted resource and reduce effect on nature. Especially resupply ground water resource, reduce effect of pollutants and urban heat island can be regarded as advantages of pervious concretes. Since limited strength properties of pervious concrete, it has not used as much as conventional concrete up to now. However, with development in additive agents technology and rising in environmental consciousness pervious concrete's name has been heard more frequently than ever before. In this study aggregate gradation, which affects physical properties of pervious concrete, was investigated. At the end of the study, it was seen that addition of sand could increase substantially compressive strength. However, preliminary test should be carried out to determine the threshold of sand addition level.
\end{abstract}

Keywords: Pervious concrete, Pervious concrete technology, Permeability

\footnotetext{
*Sorumlu yazar (Corresponding author): Ahmet AKKAYA, aakkaya@cu.edu.tr
} 


\section{GíRiş}

Artan nüfus, çevre kirliliği ve daha konforlu yaşama arzusu araştırmacıları yeni arayışlara yöneltmektedir. $\mathrm{Bu}$ amaç doğrultusunda geçirimli betonlar umut veren bir yapı malzemesidir.

$\mathrm{Bu}$ beton kullanılarak yapılan kaplamalar poroz yapısı sayesinde birçok avantaja sahiptir. Yağmur suyunu hılıca zemine doğru süzerek yer altı su kaynaklarını zamanla yenilemesi, taşı seslerini absorbe ederek konforlu bir çevre imkanı sunması, yağmurlu günlerde geçirimli beton kaplama yüzeyinde su birikintisi oluşmaması, kaplamanın geceleri parlamaması, yeryüzündeki 1sı ve nemi ayarlayarak 1sı adası oluşumunun azalmasına katkı sağlaması geçirimli beton kaplama kullanımının avantajları arasında siralanabilir [1].

Barrett ve arkadaşları [2] arazi gelişiminin hızlanmasıyla birlikte geçirimsiz kaplama alanının artabileceği ve bunun sonucunda yağmursuyu akışı ile kirlilik yükünün yükseleceği sonucuna varmışlardır, [3]. Geleneksel yağmursuyu yönetim yaklaşımında akış ve kirlenmeyi azaltmak için fazla yağmur suyunu sahada tutma ve geciktirme önceliği üzerine yoğunlaşılmıştır, [4]. Geçirimli beton kaplama teknolojisi bekletme havuzu, yağmursuyu hendeği ve diğer yağmursuyu yönetme araçlarına duyulan ihtiyacı gidererek daha etkili arazi kullanımı imkânı sunmaktadır [5].

Geçirimli beton kullanımının bir diğer avantajıysa şehir 1S1 adası etkisini azaltmasıdır. Güneş 1şığını gün boyunca absorbe eden beton ve asfalt gibi kaplamalar, şehir 1sı adası oluşumunun nedenlerindendir. $\mathrm{Bu}$ hadise, 1sinan ortamı soğutmak için ihtiyaç duyulan enerji miktarını arttırmaktadır [6].

Geçirimli betonlar birçok faydalı özelliği sayesinde, sürdürülebilir yapılar ve altyapı çalışmaları açısından önemli yeni teknolojilerden birisidir [7]. Ancak, geçirimli betonların kaplama malzemesi olarak uygulanması özellikle gelişmekte olan ülkelerde malzeme hazırlanması, test edilmesi ve bunun yanı sıra inşaat uygulamaları açısından standart eksikliğinden dolayı hala denenmemiştir [8]. Yapılan literatür araştırmalarında geçirimli betonlarla ilgili ülkemizde sınırlı sayıda çalışma yapıldığı görülmektedir. $\mathrm{Bu}$ makale kapsamında geçirimli betonların fiziksel özelliklerini etkileyen önemli parametrelerden gradasyonun basınç dayanımına etkisi incelenmiştir. Şekil 1'de bir geçirimli beton yüzeyi görülmektedir.

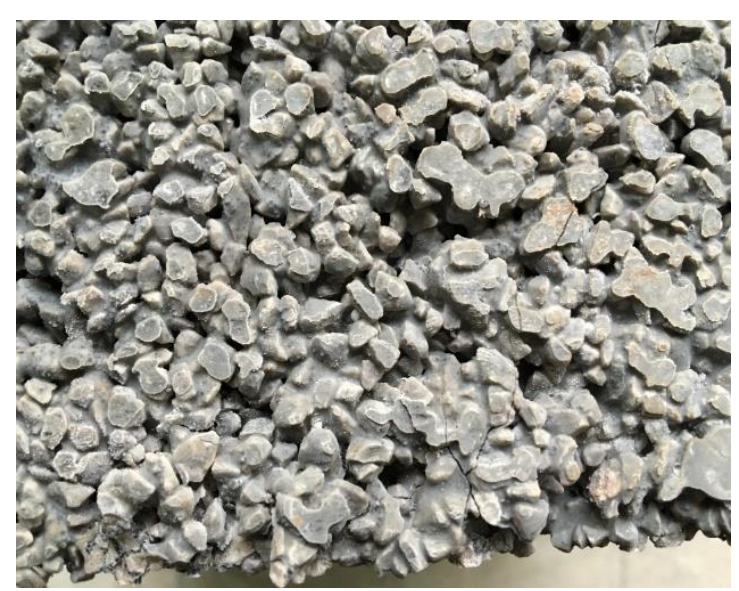

Şekil 1. Geçirimli beton yüzey görünümü

\section{GEÇIRIMLİ BETON}

ACI 522R-2010'a [9] göre geçirimli betonlar süreksiz granülometriye sahip birbirleriyle bağlantılı, bağlantısız ve kapiler boşluklar içeren materyallerdir [8]. Geçirimli betonlar çok az veya hiç ince agrega içermemekle birlikte bağlayıcı malzemeler, iri agrega ve su karıșımından oluşmakta olup; genel olarak \%15 ile \%25 arasında boşluk içermektedir [10]. Tasarım açısından düşünüldüğünde su/çimento oranı betonların önemli parametrelerindendir. Geçirimli betonlarda 0,27-0,30 arası su/çimento oranı, uygun kimyasal katkı eklentileriyle birlikte düzenli olarak kullanılmaktadır. $\mathrm{Bu}$ oran 0,34 ve 0,40'a kadar başarılı bir şekilde kullanılmıştır [5].

Geçirimli betonlarda dayanım ve su/çimento oranı arasındaki ilişki belirgin değildir. Karışım hazırlanırken su miktarı sıkı biçimde denetlenmelidir. Doğru su miktarı; avuç dolusu top haline getirilen numuneyi, boşluklu yapısını 
kaybetmeyerek ufalanmayacak hale getirecek su miktarı olarak tanımlanmıştır [5]. Geçirimli betonlarda agrega/bağlayıcı oranı da önemli bir parametre olmaktadır. Agrega/çimento oranı 4:1'den 6:1'e kadar değişmekte olup, geleneksel beton karışımlarında \%60-\%75 aralığında değişmekte olan agrega hacmine karşın, geçirimli betonlarda bu oran \%50-\%65 aralığındadır [8].

\section{3. ÖNCEKİ ÇALIŞMALAR}

\subsection{Geçirimli Beton Agregaları}

Geçirimli betonlarda ince agrega içeriği sınırlı ve iri agrega gradasyonu dar tutulmaktadır [5]. Literatür araştırmalarında agrega tipi ve gradasyonunun geçirimli betonun mekanik ve geçirimlilik özelliklerine olan etkisini inceleyen bir çok çalışmaya rastlanmıştır.

Kevern ve arkadaşları [11] tarafindan gerçekleştirilen bir çalışmada 17 kaynaktan temin edilen agregaların donma çözünme dayanımı üzerindeki etkisi incelenmiştir. Sonuçta agregaların özgül ağırlık, aşınma dayanımı, gradasyon ve su emme kapasitesi özelliklerinin donma çözünme hasarını kontrol etmede önemli rol oynayacağı bulunmuştur.

Jain ve Chouhan [12] tarafindan yapılan bir çalışmadaysa agrega şekillerinin geçirimli beton basınç dayanımı ve permeabilitesi üzerindeki etkisi incelenmiştir. Sonuçlara göre agrega köşelilik sayısına ters olarak basınç dayanımının değiştiği ayrıca düşük köşelilik sayılı agregalarda düşük permeabilite değeri ve yüksek basınç dayanımı elde edildiği bildirilmiştir.

Cosic ve arkadaşları [13] ise yapmış oldukları çalışmada agrega tipi ve boyutunun geçirimli beton özellikleri üzerindeki etkisini incelemişlerdir. Sonuçlara göre yüksek miktarda düşük boyutlu agrega kullanımının yüksek yoğunluklu bir geçirimli beton oluşturduğu, ayrıca yüksek eğilme dayanımı elde edildiği belirtilmiştir. Ayrıca geçirimli beton etkililiğini hesaplamada temel parametre olan bağlantılı porozitenin agrega tipinden, agrega boyutuna göre daha çok etkilendiği bulunmuştur.

\subsection{Bağlayıcı Malzemeler}

Geleneksel betonda olduğu gibi portland çimento ve katkılı çimento geçirimli betonlarda da kullanılabilir [5]. Araştırmacılar silis dumanı ve uçucu kül gibi ikame bağlayıcı materyalleri de geçirimli beton karışımlarında kullanmışlardır [8]. Fu ve arkadaşları [14] tarafından yapılan çalışmada alkali aktivasyonlu cüruf da bağlayıcı malzeme olarak denenmiştir.

Sonuç olarak uygun miktarda alkali aktivasyonlu cüruf kullanımının geçirimli betonların mekanik dayanımını geliştirebileceği belirtilmiştir. Aynı çalışmada farklı oranlarda silis dumanı katkısı içeren geçirimli betonların mekanik özellikleri de incelenmiştir. Deneyler sonucunda bağlayıcısı $\% 10$ silis dumanı içeren numunelerin kontrol numunesinden ve daha yüksek silis dumanı içeren numunelerden üstün mekanik dayanım gösterdiği bulunmuştur [14].

\subsection{Katkı Maddeleri}

Geçirimli betonlarda da konvansiyonel betonlarda olduğu gibi katkı malzemeleri kullanılabilmektedir. Hızlı priz almasından dolayı priz geciktirici ve hidratasyon düzenleyici yaygın olarak kullanılmaktadır [5]. Geçirimli betonlarda da hava sürükleyici katk1 maddesinin donma çözünme dayanımını geliştirdiği bildirilmiştir $[4,15]$. İncelenen çalışmalarda su azaltıcı katkı maddelerine sıklıkla başvurulduğu gözlenmiştir.

\subsection{Basınç Dayanımı}

Konvansiyonel betonun olduğu kadar geçirimli betonlarında basınç dayanımları önemlidir. Geçirimli betonların basınç dayanımını bulmak üzere yapılan çalışmalarda genel olarak geleneksel betonlar için hazırlanan deney yöntemleri kullanılmıştır. Geçirimli betonların poroz yapısı nedeniyle dayanımları düşük çıkmaktadır [1]. Tipik geçirimli beton basınç dayanım değeri $17 \mathrm{MPa}$ civarındadır [5]. Geçirimli betonların basınç dayanımlarını yükseltmek için birçok çalışma gerçekleştirilmiştir. 
Chen ve arkadaşları [16] hem polimer katk1 modifiyeli hemde ikame bağlayıı malzeme modifiyeli geçirimli betonlarla yüksek basınç dayanımı değerlerinin elde edilebileceğini bulmuşlardır. (poroziteye bağlı olarak 28 günlük değeri 32-46 MPa)

Zhong ve Wille [17] silis duman1, silis tozu, su azaltıcı katkı malzemesi ile geçirimli betonların basınç dayanımı değerlerinin ciddi miktarda artış gösterdiğini bulmuştur. Sonuç olarak uygun şekilde dizayn edildiğinde $50 \mathrm{MPa}$ basınç dayanımını geçen, $1 \mathrm{~mm} / \mathrm{sn}$ permeabilite değerini aşan, kabul edilebilir donma çözünme dayanımı gösterebilen geçirimli betonların elde edilebileceği belirtilmiştir.

Yang ve Jiang [1] küçük boyutlu agrega kullanımı, silis dumanı ve süper akışkanlaştırıcı katkı maddelerinin geçirimli betonların dayanımını geliştirdiğini bildirmiştir.

Rehder ve arkadaşları [18] lif katkı eklentili geçirimli betonları test etmişlerdir. Genel olarak basınç dayanımına lif eklenmesinin katkısının olmadığı sonucuna ulaşmışlardır. Ayrıca boşluklu yap1 özellikleri arasında porozitenin basınç dayanımı üzerinde maksimum etki gösterdiği bulunmuştur.

\subsection{Eğilme Dayanımı, Kırılma Tokluğu ve Yorulma}

Özellikle sıkıştırma derecesi, porozite, agrega/çimento oranı gibi birçok faktör geçirimli betonların eğilme dayanımı değerlerini etkilemektedir. Ancak tipik geçirimli beton uygulama tasarımları eğilme dayanımı ölçümüne ihtiyaç duymamaktadır [5]. Rehder ve arkadaşları [18] lif hacmi oranının artmasıyla kırılma tokluğunun artmasına rağmen, kırılma tokluğunun temel olarak porozite seviyesine bağlı olduğunu bulmuşlardır. Chen ve arkadaşları [16] hem polimer katk1 modifikasyonu ile hemde ikame bağlayıcı malzeme modifikasyonu yöntemleriyle elde edilen geçirimli betonların konvansiyonel geçirimli betonlara göre yorulma özelliklerini geliştirdiğini bulmuştur. Ancak, polimer katkı modifikasyonlu geçirimli betonların her gerilme seviyesinde ikame bağlayıcı malzeme modifikasyonlu geçirimli betondan daha yüksek kırılma tokluğu ve daha uzun yorulma ömrü gösterdiği belirtilmiştir.

\subsection{Aşınma ve Donma Çözünme}

Genel amaçlı kaplama malzemesi olarak kullanılma imkanı bulunduğundan geçirimli betonların aşınma ve donma çözünme özellikleri de yapılan çalışmalar kapsamında test edilmiştir. Geçirimli betonların aşınma dayanımlarını bulmak için Dong ve arkadaşları [19] Cantabro testi, yüklenmiş teker aşınma testi ve yüzey aşınma testini kullanarak elde ettikleri sonuçları karşılaştırmışlardır. Çalışmanın sonucunda daha ince iri agrega, latex ve/veya lif eklenmesinin geçirimli betonların aşınma dayanımını arttırdığı görülmüştür. Gaedicke ve arkadaşları [20] farklı agrega tiplerinden yapılmış geçirimli betonların aşınma dayanımlarını darbe aşınma ve yüzeysel aşınma testini kullanarak tespit etmişlerdir. Test sonuçlarına göre ince çakıl kullanılarak yapılan karışımlar kırma taş agregalarla yapılan karışımlardan daha düşük aşınma dayanımı göstermişlerdir. Bu farklılığa kırma taş agregaların çimento hamuruna bağlanmasını güçlendirebilecek, gelişmiş yüzeysel sertlik ve kenetlenmenin sebep olabileceği sonucuna varılmıştır. Başka bir çalışmada atık lastik parçalarının aşınma dayanımı üzerindeki etkisi de incelenmiştir. Sonuçta atık lastik kullanımının aşınma ve donma çözünme dayanımını geliştirdiği bulunmuştur [21].

Geçirimli betonlar boşluklu yapısından dolayı donma çözünme aşınmasına karşı da hassastır. Araştırmacılar hava sürükleyici katkı kullanılması [4], küçük boyutlu agrega kullanımı, silis dumanı ve süper akışkanlaştırıcı kullanılması [1] gibi uygulamaların geçirimli betonların donma çözünme dayanımlarını geliştirdiği sonucuna ulaşmışlardır.

Geçirimli betonların donma çözünme dayanımlarının değerlendirilmesi için uygun bir test metodu ile ilgili fikir birliğine henüz 
varılamamıştır. ASTM C 666A [22] kaplamaları en hizlı bozulma potansiyeli olan doygun halde test etmektedir. Geçirimli betonlarda doygun hale gelerek daha çabuk erken bozulmalara yol açacacak agregalar etrafindaki ince beton tabakalarından dolayı, donma çözünme dayanımı üzerindeki agrega etkisi geleneksel betonunkinden farklı olabilmektedir [11].

\subsection{Geçirimlilik Özellikleri}

Geçirimli betonlarda en çok aranan özelliklerden olan su iletimi, yüzeyden tabana birbiriyle bağlantılı boşluklar sayesinde olmaktadır. Taşınımla ilgili olan özellikler suyu yüzeyden tabana transfer edip, nihai olarak taban suyunun beslenmesine yardım etmektedirler [8]. Geçirimli betonlardaki toplam porozite birbirleriyle bağlantılı boşluklar ve kapalı uçlu boşlukların toplamıdır ve su içinde tartma metoduyla hesaplanabilir [13]. Suyun taşınımına yardım eden birbirleriyle bağlantılı boşluk yapıları ayrıca efektif porozite olarak da anılmaktadır [8].

Permeabilite deneyleri, geçirimlilik özelliklerini tespit etmek için olmazsa olmazdır. Qin ve arkadaşları [23] geçirimli betonlarda permeabilite ölçümlerinde düşen seviyeli permeabilite testi kullanılmasının, sabit seviyeli permeabilite testi kullanılmasından daha yüksek sonuç verdiğini belirtmişlerdir. Düşen seviyeli permeabilite testinin başlangıç ve bitiş su seviyesi seçimi hesaplanan permeabilite değerini etkilediği, su seviyesinin sıfıra yaklaştıkça bu farkın azaldığı ve bu korelasyondan dolayı geçirimli betonun permabilite değerinin uygulanan basınç ve test metoduyla birlikte rapor edilmesi gerektiğini vurgulamışlardır.

\section{MATERYAL VE METOT}

\subsection{Materyal}

\subsection{1 Çimento}

$\mathrm{Bu}$ çalışmadaki karışımlarda Adana Çimento Sanayii T.A.Ş.'de üretilmiş CEM I 52,5 R beyaz portland çimentosu ve CEM V/A (S-P) 32,5 R kompoze çimento kullanılmıştır.

\subsubsection{Silis Dumanı}

İlk iki karışımda ikame bağlayıcı olarak sırasıyla çimento ağırlığının \% 25'i ve \% 15'i oranlarında, diğerlerinde çimento ağırlığının \% 10'u oranında Oyak Beton'dan temin edilen silis dumanı kullanılmıştır.

\subsubsection{Süper Akışkanlaştırıcı}

İlk karışım hariç, diğer karışımlarda bağlayıcı ağırlığının \% 2,5'i kadar BASF MasterGlenium 51 tipi polikarboksilik eter esaslı süper akışkanlaştırıcı kullanılmıştır.

\subsection{Numune Boyutları}

Deneyde $15 \times 15 \times 15 \mathrm{~cm}$ lik küp kalıplar ve $15 \mathrm{~cm}$ çapında $30 \mathrm{~cm}$ yüksekliğinde silindir numuneler kullanılmıştır.

\subsection{Metot}

Malzemeler betoniyer yardımıyla karıştırılmış olup; ilk karıştırmanın ardından tavaya dökülerek homojen kıvam elde edilene kadar kürek ve mala yardımıyla karıştırma işlemi devam etmiştir. Putman ve Neptune silindir numuneler üzerinde Proktor çekici kullanılarak yapılan sıkıştırmanın saha koşullarındaki geçirimli beton kaplamanın özelliklerini iyi temsil ettiğini belirtmiştir [24]. Bu nedenle karışımlar standart proktor çekiciyle sıkıştırılmıştır.

Karışımların 7 günlük basınç dayanımları incelenmiş olup; numuneler deney gününe kadar kür havuzunda bekletilmiştir. Deneyler Çukurova Üniversitesi Mühendislik Mimarlık Fakültesi İnşaat Mühendisliği Bölümü Yap1 Laboratuvarı'nda gerçekleştirilmiştir. Şekil 2'de 5 no'lu karışıma ait numuneler görülmektedir. 


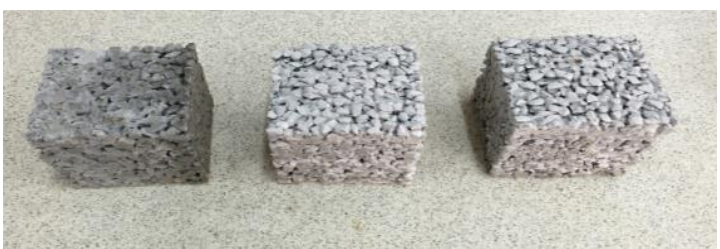

Şekil 2. 5 no'lu karışıma ait numuneler

Şekil 3'de karışımlarda kullanılan agrega granülometrileri gösterilmiştir.

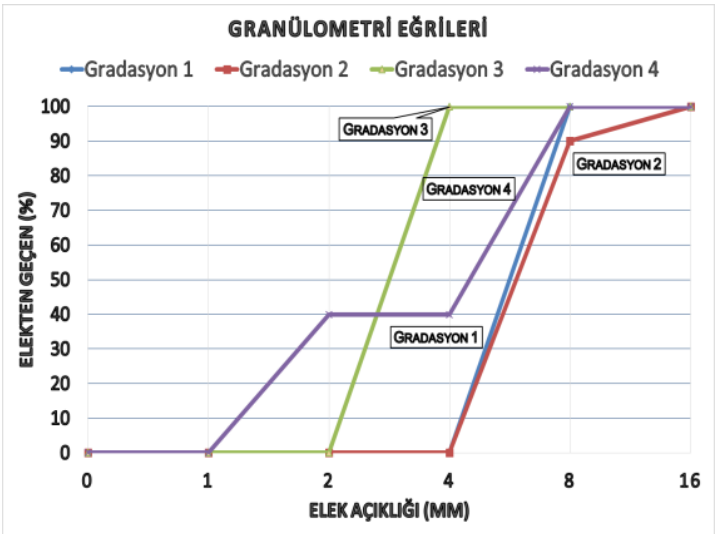

Şekil 3. Karışımlarda kullanılan agrega granülometrileri

Kırmataş kireç esaslı agregalar karışımda kullanılmıştır. Kullanılan agregaların özgül ağırlık değerleri Çizelge 1'de gösterilmiştir.

Çizelge 1. Agrega özgül ağırlık değerleri Agrega boyutları Özgül ağırlık değerleri

$0-5 \mathrm{~mm} \quad 2,56 \mathrm{~g} / \mathrm{cm}^{3}$

$$
5-15 \mathrm{~mm} \quad 2,69 \mathrm{~g} / \mathrm{cm}^{3}
$$

Karışım oranları Çizelge 2'de görülmektedir.

Çizelge 2. Karışım oranları

\begin{tabular}{lcccccc} 
Karışım No & $\mathbf{1}$ & $\mathbf{2}$ & $\mathbf{3}$ & $\mathbf{4}$ & $\mathbf{5}$ & $\mathbf{6}$ \\
\hline Su/Çimento & 0,24 & 0,26 & 0,28 & 0,28 & 0,28 & 0,28 \\
Agr./Bağl. & 1,61 & 1,92 & 2,31 & 2,51 & 2,51 & 2,42 \\
Gradasyon & 2 & 2 & 3 & 3 & 1 & 4 \\
Numarası & & & & & & \\
Çimento Tipi & 52,5 & 52,5 & 52,5 & 32,5 & 52,5 & 52,5 \\
& $\mathrm{R}$ & $\mathrm{R}$ & $\mathrm{R}$ & $\mathrm{R}$ & $\mathrm{R}$ & $\mathrm{R}$ \\
\hline
\end{tabular}

*: Agrega/Bağlayıcı oranı
Çizelge 2'de görülen karışım değerleri ile geçirimli betonların basınç dayanımı değerlerinin değişimi incelenmiştir. Altıncı karışımda çimento hamurunun gradasyona kum eklenmesiyle nasıl sonuç vereceği test edilmiştir. İlk beş karışım boşluklu yapıda olup, sadece altıncı karışım boşluklu yapıya sahip değildir. Şekil 4'te 6 no'lu karışımla hazırlanmış küp numuneye ait kırılma şekli görülmektedir.

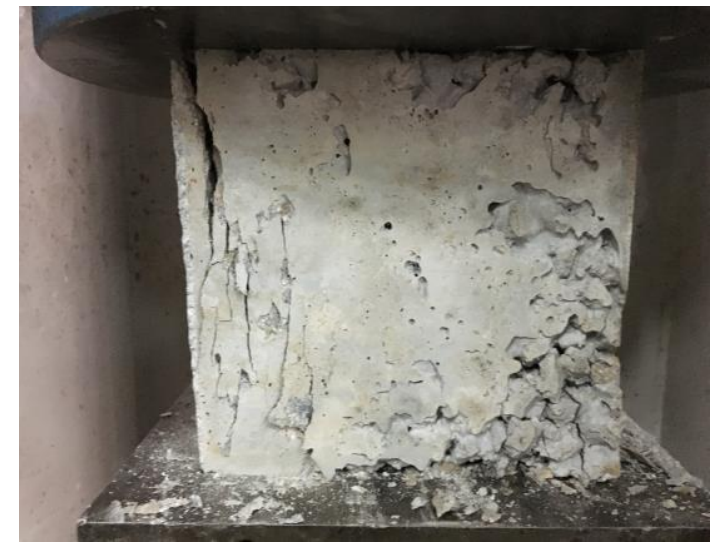

Şekil 4. 6 no'lu karışımla hazırlanmış küp numune kırılma şekli

Deneyler sonunda elde edilen basınç dayanımı değerleri Çizelge 3'de görülmektedir. 1 ve 2 no'lu karışımlara ait deneylerde $15 \mathrm{~cm}$ çapında $30 \mathrm{~cm}$ yüksekliğinde silindir numuneler kullanılırken, diğer karışımlarda $15 \times 15 \times 15 \quad \mathrm{~cm}$ 'lik küp numuneler kullanılmıştır.

Çizelge 3. Basınç dayanımı değerleri

\section{Karıșım No}

\section{Basınç Dayanımı}

(MPa)

\begin{tabular}{lc}
\hline 1 & 1,6 \\
2 & 8,3 \\
3 & 23,9 \\
4 & 12,7 \\
5 & 19,5 \\
6 & 72,3 \\
\hline
\end{tabular}




\section{SONUÇ VE ÖNERİLER}

Geçirimli betonlar insanoğlunun doğaya olan olumsuz etkisini azaltma, yaşam konforunu arttırma ve yaşadığımız çevreyi daha yaşanılır hale getirme amacıyla yapılan çalışmalardandır. Ancak, düşük dayanım değerlerinden dolayı bugüne kadar geniş kullanım imkanı olmamıştır.

Karışım 1'de bağlayıcılar varlık gösterememiştir. Karışım 2'de oldukça kuru kıvamlıdır. İlk iki karışımın düşük basınç dayanım değerlerinin, karışımlarda gerekli su miktarından daha az su kullanıldığından kaynaklandığına kanaat getirilmiştir.

CEM V/A (S-P) 32,5 R çimento ile yapılan 4 no' lu karışım numunelerinin CEM I 52,5 R çimento kullanılarak yapılan 3 no'lu karışım numunelerinden daha düşük basınç dayanımı değerine sahip olduğu görülmüştür. Agrega/bağlayıcı oranları birbirine yakın olduğundan aradaki farkın ağırlıklı olarak çimento tipinden kaynaklandığı düşünülmektedir.

İlk beş karışımda sadece 3 no'lu karışımda $20 \mathrm{MPa}$ değerinin üzerine çıkılabilmiştir. 6 no'lu karışıma kum eklenerek agrega granülometrisinin etkisi de incelenmiştir. Sonuçta basınç dayanımı değeri 5 no' lu karışımda 19,5 MPa seviyesindeyken, 6 no'lu karışıma ait numunede 72,3 MPa seviyesine çıkmıştır. Ancak bu seferde geçirimli beton, boşluklu yapısını kaybetmiştir.

Elde edilen sonuçlara göre agrega granülometrisinin geçirimli betonların basıç dayanımlarını etkileyen önemli parametrelerden olduğu görülmüştür. Genelde iri agregalarla yapılan geçirimli beton karışımlarına kum eklenerek basınç dayanımlarının büyük oranda yükseltilebileceği anlaşılmıştır. Ancak geçirimlilik özelliklerini olumsuz etkilemeyecek kum eklentisi eşik değerinin belirlenmesi için ön çalışmalar yapılmalıdır. Bu çalışmadaki karışımlar arasındaki basınç dayanımı farklılıklarının agrega/bağlayıcı oranından ziyade gradasyon ve çimento tipinden kaynaklandığı düşünülmektedir. Geçirimli betonlarla ilgili yapılacak her çalışma standart ve yönetmeliklerin oluşturulmasına katk1 sağlayacağından, oldukça değerlidir.

\section{KAYNAKLAR}

1. Yang, J., Jiang, G., 2002. Experimental Study on Properties of Pervious Concrete Pavement Materials, Cement and Concrete Research, 33(3): 381-386.

2. Barrett, M.E., Jr, L.B.I., Jr, J.F.M., Charbeneau, R.J., 1998. Characterization of Highway Runoff in Austin, Texas, Area, Journal of Environmental Engineering, 124(2): 131-137.

3. Haselbach, L.M., Valavala, S., Montes, F., 2005. Permeability Predictions for SandClogged Portland Cement Pervious Concrete Pavement Systems, Journal of Environmental Management, 81(1): 42-49.

4. Ghafoori, N., Dutta, S., 1995. Laboratory Investigation of Compacted No-Fines Concrete for Paving Materials. Journal of Materials in Civil Engineering, 7(3): 183-191.

5. Tennis, P.D., Leming, M.L., Akers, D.J., Association N.R.M.C., 2004. Pervious Concrete Pavements, Portland Cement Association Skokie, IL.

6. Urban Heat Island, Wikipedia, https://en.wikipedia.org/wiki/Urban_heat_islan d, 27.05.2016, 17:56.

7. Nguyen, D.H., Sebaibi, N., Boutouil, M., Leleyter, L., Baraud, F., 2014. A Modified Method for the Design of Pervious Concrete Mix, Construction and Building Materials, 73: 271-282.

8. Chandrappa, A.K. Biligiri, K.P., 2016. Pervious Concrete as a Sustainable Pavement Material-Research Findings and Future Prospects: A State-of-the-Art Review, Construction and Building Materials, 111: 262274.

9. American Concrete Institute, 522R-10, Report on Pervious Concrete.

10. National Ready Mix Concrete Association (NRMCA), NRMCA-Concrete in Practice-38 (CIP-38), http://www.nrmca.org/aboutconcrete /cips/38p.pdf, 26.05.2016, 16:30. 
11. Kevern, J.T., Wang, K., Schaefer, V.R., 2010. Effect of Coarse Aggregate on the FreezeThaw Durability of Pervious Concrete. Journal of Materials in Civil Engineering, 22(5): 469-475.

12. Jain, A.K., Chouhan, J.S., 2011. Effect of Shape of Aggregate on Compressive Strength and Permeability Properties of Pervious Concrete, International Journal of Advanced Engineering Research and Studies EISSN2249-8974, 1(1): 120-126.

13. Ćosić, K., Korat, L., Ducman, V., Netinger, I., 2015. Influence of Aggregate Type and Size on Properties of Pervious Concrete, Construction and Building Materials, 78: 69-76.

14. Fu, T.C., Yeih, W., Chang, J.J., Huang, R., 2014. The Influence of Aggregate Size and Binder Material on the Properties of Pervious Concrete. Advances in Materials Science and Engineering, p:17.

15. Shu, X., Huang, B., Wu, H., Dong, Q. Burdette, E.G., 2011. Performance Comparison of Laboratory and Field Produced Pervious Concrete Mixtures. Construction and Building Materials, 25: 3187-3192.

16. Chen, Y., Wang, K., Wang, X., Zhou, W., 2013. Strength, Fracture and Fatigue of Pervious Concrete, Construction and Building Materials, 42: 97-104.

17.Zhong, R., Wille, K., 2015. Material Design and Characterization of High Performance Pervious Concrete, Construction and Building Materials, 98: 51-60.

18. Rehder, B., Banh, K., Neithalath, N., 2014. Fracture Behavior of Pervious Concretes: The Effects of Pore Structure and Fibers, Engineering Fracture Mechanics, 118: 1-16.

19. Dong, Q., Wu, H., Huang, B., Shu, X., Wang, K., 2012. Investigation into Laboratory Abrasion Test Methods for Pervious Concrete, Journal of Materials in Civil Engineering, 25(7): 886-892.

20. Gaedicke, C., Marines, A., Miankodila, F., 2014. Assessing the Abrasion Resistance of Cores in Virgin and Recycled Aggregate Pervious Concrete, Construction and Building Materials, 68: 701-708.

21. Gesoğlu, M., Güneyisi, E., Khoshnaw, G., İpek, S., 2014. Abrasion and Freezing-
Thawing Resistance of Pervious Concretes Containing Waste Rubbers, Construction and Building Materials, 73: 19-24.

22. ASTM International, ASTM C 666/C666M-03, ASTM Standard Test Method of Resistance of Concrete to Rapid Freezing and Thawing, 2003.

23. Qin, Y., Yang, H., Deng, Z., He, J., 2015. Water Permeability of Pervious Concrete Is Dependent on the Applied Pressure and Testing Methods. Advances in Materials Science and Engineering, Hindawi Publishing Corporation, 1-6.

24. Putman, B.J., Neptune, A.I., 2011. Comparison of Test Specimen Preparation Techniques for Pervious Concrete Pavements, Construction and Building Materials, 25: 3480-3485. 